\title{
Laparoscopic Treatment of Hepatic Abscess Caused by an Ingested Foreign Body
}

\author{
Dong Hee Kim, M.D., Ph.D., Min Sung Kim, M.D., Jin Wan Park, M.D., Yeon Soo Chang, M.D., Ph.D. \\ Department of Surgery, Eulji Medical Center, Eulji University College of Medicine, Seoul, Korea
}

Pyogenic hepatic abscess caused by an ingested foreign body is extremely uncommon, and reports on the laparoscopic treatment for it are very rare. We report here on a case of hepatic abscess caused by an ingested chicken bone which was treated with a laparoscopic approach. A 61-year-old man visited an emergency room with the chief complaints of high fever. He was diagnosed with pyogenic liver abscess that contained a sharp calcified foreign body seen on a CT-scan. At first, percutaneous transhepatic drainage of the abscess was performed to achieve recovery of the patient's condition. Subsequent laparoscopic exploration found and removed the foreign body in the lesser sac. The foreign body turned out to be an ingested chicken bone. The patient was discharged on the 10th day after surgery.

Keywords: Hepatic abscess, Foreign body, Laparoscopy
Received November 25, 2019

Accepted November 28, 2019

Corresponding author

Yeon Soo Chang

Department of Surgery, Eulji Medical Center, Eulji University College of

Medicine, 68 Hangeulbiseok-ro,

Nowon-gu, Seoul

01830, Korea

Tel: +82-2-970-8688

Fax: +82-2-970-8227

E-mail: cutdowngs@naver.com ORCID:

https://orcid.org/0000-0002-6570-5920

Copyright $\odot 2019$ The Journal of Minimally Invasive Surgery. All rights reserved.
This is an Open Access article distributed under the terms of the Creative Commons Attribution Non-Commercial License (http:// creativecommons.org/licenses/by-nc/4.0/) which permits unrestricted non-commercial use, distribution, and reproduction in any medium, provided the original work is properly cited.

\section{INTRODUCTION}

An ingested foreign body commonly passes through the gastrointestinal tract without any problems, and a hepatic abscess is serious septic condition that is usually caused by periportal and biliary infection.

Pyogenic hepatic abscess caused by an ingested foreign body is extremely uncommon and reports of laparoscopic treatment are very rare. We report here on a case of hepatic abscess caused by an ingested chicken bone which was treated with a laparoscopic approach.

\section{CASE REPORT}

A 61-year-old man visited our emergency room with the chief complaints of sustained high fever for 8 days. He had no special medical history, and he didn't recall any event of foreign body ingestion.

His vital signs showed a high fever of $40^{\circ} \mathrm{C}$. On physical examination, no specific gastrointestinal signs or symptoms were found. Simple X-ray of the abdomen showed normal findings. The laboratory results showed leukocytosis (12,300/ $\mathrm{mm}^{3}$ ), a normal level of hepatic enzymes (AST: $31 \mathrm{IU} / \mathrm{L}$ and ALT: $36 \mathrm{IU} / \mathrm{L})$, and total bilirubin $(0.7 \mathrm{mg} / \mathrm{dl})$, and elevated levels of both creatinine $(1.58 \mathrm{mg} / \mathrm{dl})$ and C-reactive Protein $(7.99 \mathrm{mg} / \mathrm{dl})$. The enhanced abdominal CT scan revealed a 5.8 $\mathrm{cm}$ sized hypodense mass in the left hepatic lobe and a $3 \mathrm{~cm}$ sized sharp calcified foreign body between the left hepatic lobe and gastric antrum (Fig. 1). He was diagnosed with a pyogenic liver abscess that contained a foreign body.

Gastroduodenoscopy showed an edematous, hypertrophic mucosal lesion that had a central erosion at the lesser curva- 


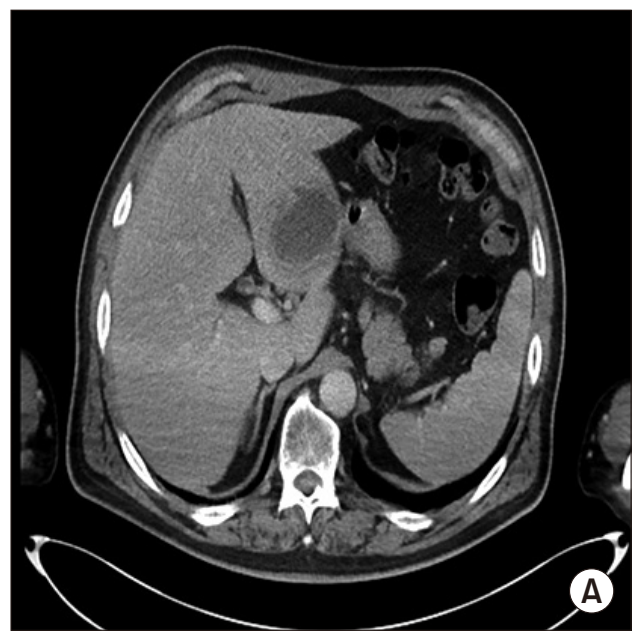

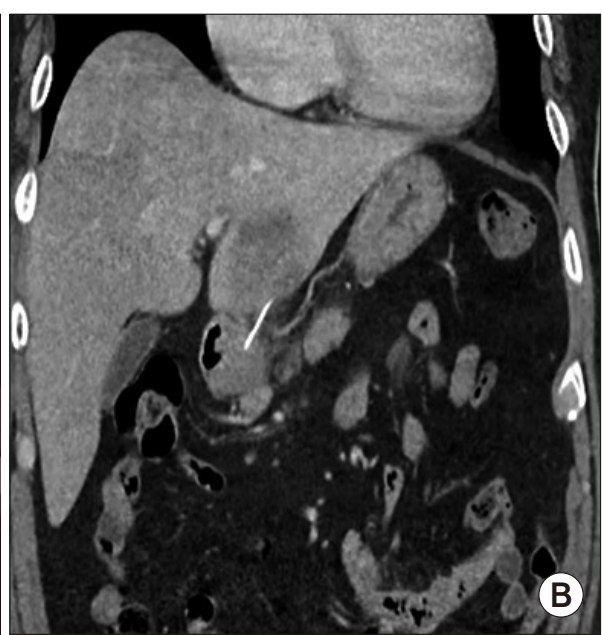

Fig. 1. (A) $5.8 \mathrm{~cm}$ sized rim enhanced hypodense mass at left hepatic lobe (hepatic abscess). (B) $3 \mathrm{~cm}$ sized sharp linear foreign body between left hepatic lobe and gastric antrum.

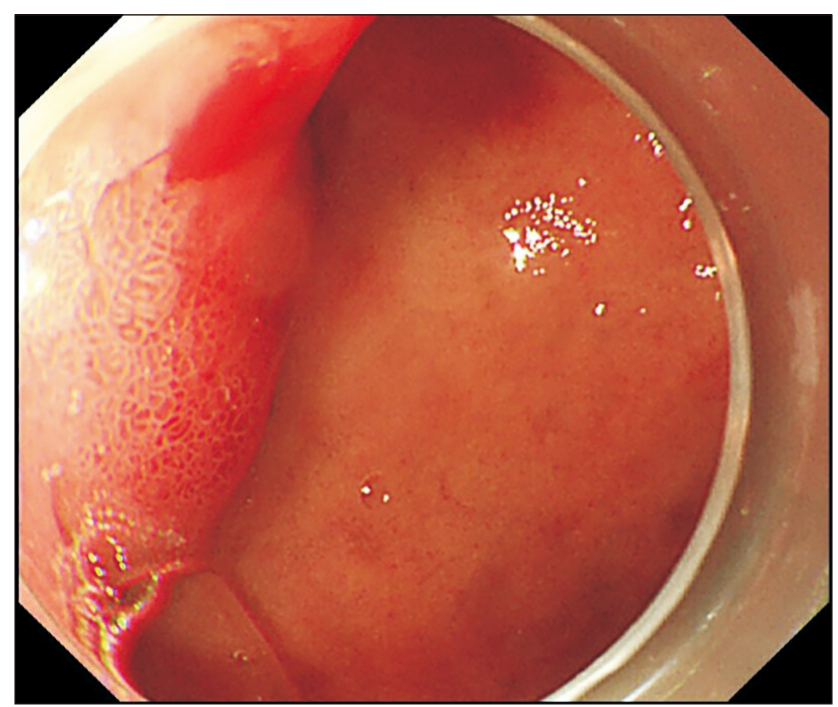

Fig. 2. Endoscopic finding showed edematous mucosal lesion which has central erosion at lesser curvature of distal stomach. No foreign body was found.

ture of the distal stomach but didn't find a foreign body in the stomach and duodenum (Fig. 2).

Interventional percutaneous transhepatic drainage of the abscess and administration of antibiotics was the first step of treatment for the patient's conditions.

Streptococcus constellatus species was isolated from the pus culture, which suggested that the pathogen of the hepatic abscess was derived from the pharynx.

Subsequent laparoscopic exploration was performed seven days after abscess drainage. A dense inflammatory adhesion was found between the hepatoduodenal ligament and the left lobe of the liver. Careful dissection found and removed the foreign body in the lesser sac (Fig. 3).
The pathologic findings of the foreign body showed bony tissue with diffuse hemorrhage and focal inflammatory cells and it was turned out to be an ingested chicken bone.

He was discharged on the 10th day after surgery.

\section{DISCUSSION}

An ingested gastrointestinal foreign body usually passes through the gut without any special incident, and this particular medical situation is encountered in less than $1 \%$ of patients. ${ }^{2}$ Pyogenic hepatic abscess is usually derived from a septic condition of the portal-biliary system, and this can be a fatal condition. Pyogenic hepatic abscess caused by an ingested foreign body is a very unusual case and laparoscopic treatment of it has rarely been reported. ${ }^{3-7}$

Although a hepatic abscess has classic symptoms of fever, pain and jaundice, those patients with hepatic abscess caused by a gastrointestinal foreign body usually manifest nonspecific symptoms (fever, anorexia, pain, etc.) and this condition can be silent. Our patient had only high fever without any gastrointestinal symptoms. The interval between clinical presentation and foreign body ingestion can vary from one week to even after one year. ${ }^{8}$

The patient's history is very important to find the clue for making the proper diagnosis. However, most of patients, including our patient, do not remember the episode of foreign body ingestion and only $5 \%$ of patients could recall the event. ${ }^{2}$

Various kind of foreign body has been reported, which include toothpick, fish bone, chicken bone, needle, pen, etc. Among these, fish bone (33\%) is most commonly reported as the cause of hepatic abscess. ${ }^{2}$

Radiologic examination should be first step of the objective diagnostic procedure. A simple abdominal X-ray is usually performed, but its sensitivity shows a disappointing result of 39\% 

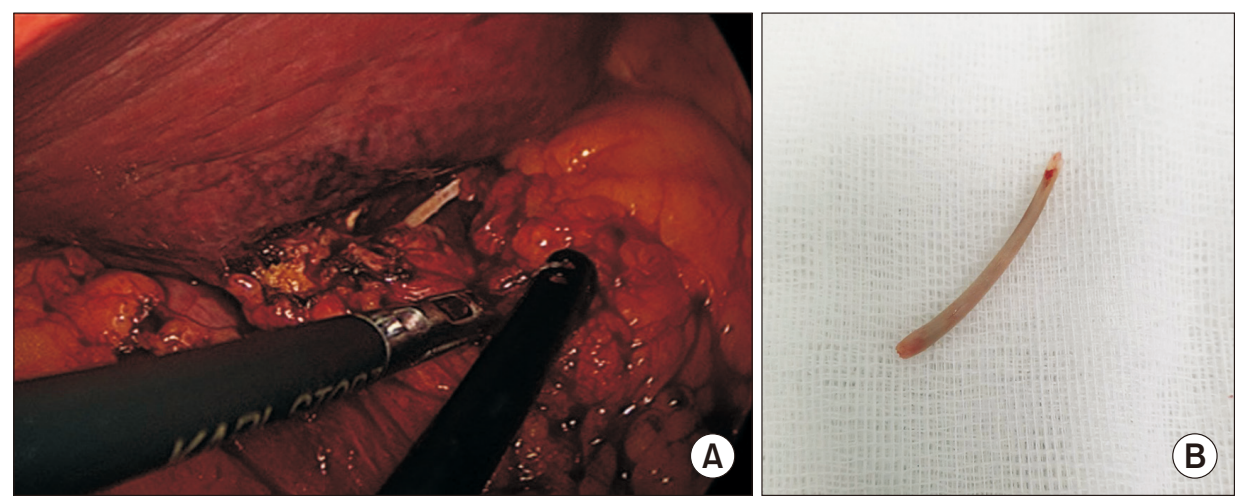

Fig. 3. (A) Laparoscopic removal of foreign body in dense inflammatory adhesion between hepatoduodenal ligament and left hepatic lobe. (B) Foreign body was ingested chicken bone. for fish bones. An abdominal CT scan is a promising diagnostic tool that can detect simultaneously the hepatic abscess and the foreign body with high sensitivity of 90\%. Endoscopy can be added for searching for the ingested foreign body if the foreign body has not fully penetrated the gastrointestinal tract.

We performed the endoscopy to search the foreign body shown on CT, but we failed to find it. The endoscopic findings showed edematous mucosal erosion at the lesser curvature of the distal stomach, which was highly suspected to be the site of perforation. Yu et al. ${ }^{1}$ and Panebianco et al. ${ }^{3}$ reported that peristaltic wave caused gradual migration of foreign body through thick gastric wall and progressive inflammatory adhesion of adjacent organs, and the omentum can surround and seal the perforation.

Since the stomach (40.9\%) and duodenum (20.5\%) are the most common sites of perforation by the foreign bodies, the left lobe of the liver is commonly affected because of its anatomical location. ${ }^{2}$ The right lobe of the liver can be affected by migration of a foreign body from the ascending colon. $\mathrm{Fu}^{-}$ jiwara et al. ${ }^{9}$ reported a hepatic abscess in the Spiegel lobe by foreign body penetration.

The principle of treatment should include adequate drainage of the hepatic abscess, complete removal of the foreign body and closure of the perforation site. ${ }^{8}$ Recurrence of abscess was reported in case that was treated conservatively without removal of the foreign body. ${ }^{10}$ Reported treatments of hepatic abscess caused by an ingested foreign body vary from conservative management, endoscopic removal of the foreign body and both laparoscopy and/or open hepatectomy. Laparoscopic treatments have rarely been reported. The laparoscopic approach can be technically challenging due to dense inflammatory adhesion around the perforated site, and the nearby liver and adjacent organs. Further, small sized foreign body buried in inflammatory tissue might be difficult to find and completely remove. Lau et al. ${ }^{11}$ reported image-guided percutaneous transhepatic removal of a fish bone from a hepatic abscess.
In conclusion, hepatic abscess caused by an ingested foreign body is very rare. Early appropriate diagnostic and therapeutic strategies should be established, including abscess drainage and removal of the foreign body. A laparoscopic approach can be useful and effective to treat this condition.

\section{ORCID}

Dong Hee Kim, https://orcid.org/0000-0001-9910-8414

Min Sung Kim, https://orcid.org/0000-0001-6370-7239

Jin Wan Park, https://orcid.org/0000-0002-3816-8357

Yeon Soo Chang, https://orcid.org/0000-0002-6570-5920

\section{AUTHORS' CONTRIBUTIONS}

Conceptualization: YSC. Formal analysis: MSK. Methodology: JWP. Writing-original draft: DHK. Writing-review and editing: YSC.

\section{CONFLICT OF INTEREST}

None.

\section{FUNDING}

None.

\section{ACKNOWLEDGMENTS}

None.

\section{REFERENCES}

1) Yu W, Yu H, Ling J, et al. Hepatic Abscess Secondary to Stomach Perforation by a Fish Bone: a Rare Cause of Hepatic Abscess. Ann Hepatol 2018;17:880-883.

2) Chong $L-W$, Sun $C-K$, Wu C-C, Sun $C-K$. Successful treatment 
of liver abscess secondary to foreign body penetration of the alimentary tract: a case report and literature review. World J Gastroenterol 2014;20:3703-3711.

3) Panebianco A, Lozito RC, Prestera A, et al. Unusual liver abscess secondary to ingested foreign body: laparoscopic management. G Chir 2015;36:74-75.

4) Tan $\mathrm{CH}$, Chang SYH, Cheah YL. Laparoscopic Removal of Intrahepatic Foreign Body: A Novel Technique for Management of an Unusual Cause of Liver Abscess--Fish Bone Migration. J Laparoendosc Adv Surg Tech A 2016;26:47-50.

5) Turaihi H, Assam J, Zanfes J, Thambi-Pillai T. Laparoscopic Treatment of a Pyogenic Hepatic Abscess Caused by Transmural Duodenal Perforation of a Toothpick. S D Med 2017;70:369-371.

6) Chou D-A, Hung M-C, Lai J-C, Huang WS-W. Pyogenic hepatic abscess induced secondary to toothpick penetration of stomach. Turk J Gastroenterol 2018;29:241-242.
7) Bekki T, Fujikuni N, Tanabe K, Amano H, Noriyuki T, Nakahara M. Liver abscess caused by fish bone perforation of stomach wall treated by laparoscopic surgery: a case report. Surg Case Rep 2019;5:2019;5:79.

8) Pérez Saborido B, Bailón Cuadrado M, Velasco López R. A liver abscess secondary to a toothpick: a rare complication of accidental foreign body ingestion. Rev Esp Enferm Dig 2019;111:167-168.

9) Fujiwara Y, Shiba H, Nakabayashi Y, Otsuka M, Yanaga K. Hepatic abscess in the Spiegel lobe caused by foreign body penetration: report of a case report. Surg Case Rep 2017;3:2017;3:24.

10) Ng CT, Htoo A, Tan SY. Fish bone-induced hepatic abscess: medical treatment. Singapore Med J 2011;52:e56-e58.

11) Lau CW, Wong KM, Gogna A. Image-guided Percutaneous Transhepatic Removal of Fish Bone from Liver Abscess. J Radiol Case Rep 2017;11:1-7. 